\title{
A high-fidelity wave-to-wire model for wave energy converters
}

\author{
Markel Penalba*, John V. Ringwood \\ Centre for Ocean Energy Research, Maynooth University, Maynooth, Co. Kildare, Ireland
}

\section{A $\quad$ R $T$ T I C C L E I I N F}

\section{Article history:}

Received 13 June 2017

Received in revised form

14 September 2018

Accepted 10 November 2018

Available online 15 November 2018

\section{Keywords:}

Wave energy

Wave-to-wire modelling

High-fidelity

Hydraulic power take-off

Multi-rate solver

\begin{abstract}
A B S T R A C T
Mathematical models incorporating all the necessary components of wave energy converters (WECs) from ocean waves to the electricity grid, known as wave-to-wire (W2W) models, are vital in the development of wave energy technologies. Ideally, precise W2W models should include all the relevant nonlinear dynamics, constraints and energy losses. This paper presents a balanced W2W model that incorporates high-fidelity models for each conversion system, and can accommodate different types of WECs, hydraulic power take-off (PTO) topologies, electric generators and grid connections. The models of the different conversion stages presented herein are efficiently implemented in the W2W model using a multi-rate integration scheme that reduces the computational requirements by a factor of 10 . Two W2W models, i.e. one with the constant-pressure hydraulic PTO configuration and one with the variablepressure configuration, are compared in this paper. Results show that a higher PTO efficiency (30\% higher for the constant-pressure configuration) does not necessarily imply a higher electricity generation ( $2 \%$ higher for the variable-pressure configuration), which reinforces the need for high-fidelity W2W models for the design of successful WECs.
\end{abstract}

๑) 2018 Elsevier Ltd. All rights reserved.

\section{Introduction}

Maximising electricity generation of wave energy converters (WECs) is vital if WECs are to become profitable and contribute to reducing greenhouse gas emissions of the energy supply sector. Control strategies play a crucial role in the power maximisation of WECs, but most research effort has focused on maximising hydrodynamic power absorption. However, the performance of each component of the powertrain may strongly impact the final power output, so the dynamics of the power take-off (PTO) must also be considered when designing model-based control strategies that truly maximise the electricity generation. For example [1] illustrates the relevance of including a non-ideal PTO in the control formulation, where an erroneous PTO model in the controller is shown to lead to a dramatic reduction of the generated power.

To accurately study the holistic performance of WECs, mathematical models that include all the components of the different conversion stages, from ocean waves to the electricity grid, known as wave-to-wire (W2W) models, are essential. Such W2W models should incorporate all the characteristic dynamics (including nonlinear dynamics when required), energy losses and constraints of the different components. The path from ocean waves to the

\footnotetext{
* Corresponding author.

E-mail address: markel.penalbaretes.2015@mumail.ie (M. Penalba).
}

electricity grid can be divided into six steps, with four conversion stages, as illustrated in Fig. 1, where control inputs appropriate to various conversion stages $(\alpha, \beta$ and $\gamma$ ) are also shown. The different conversion stages are interconnected and share variables. For example, the absorber shares the position $\left(x_{a b s}\right)$, velocity $\left(\dot{x}_{a b s}\right)$, and acceleration of the absorber $\left(\ddot{x}_{a b s}\right)$ with the hydraulic transmission system. The other variables shared in the interconnections between the different conversion stages, as illustrated in Fig. 1, are the PTO force $\left(F_{P T O}\right)$, the mechanical torque of the hydraulic motor $\left(T_{M}\right)$, the rotational speed of the generator shaft $\left(\omega_{r}\right)$, the voltage of the grid or the power converter $(V)$ and, the current generated in the electric generator $(i)$.

More insight on W2W modelling is given in Ref. [2] for a large variety of PTO systems suggested in the literature. It should be noted that, in the following, WEC refers to the whole system including all the conversion stages, as shown in Fig. 1, while the device that absorbs power from ocean waves is referred to as the absorber. As a consequence, power absorption henceforth refers to the mechanical power absorbed from the ocean waves, while the final electrical power is referred to as generated power.

\subsection{Existing wave-to-wire models}

Wave-to-wire models incorporating diverse degrees of detail have been proposed for different absorbers and PTO types, 


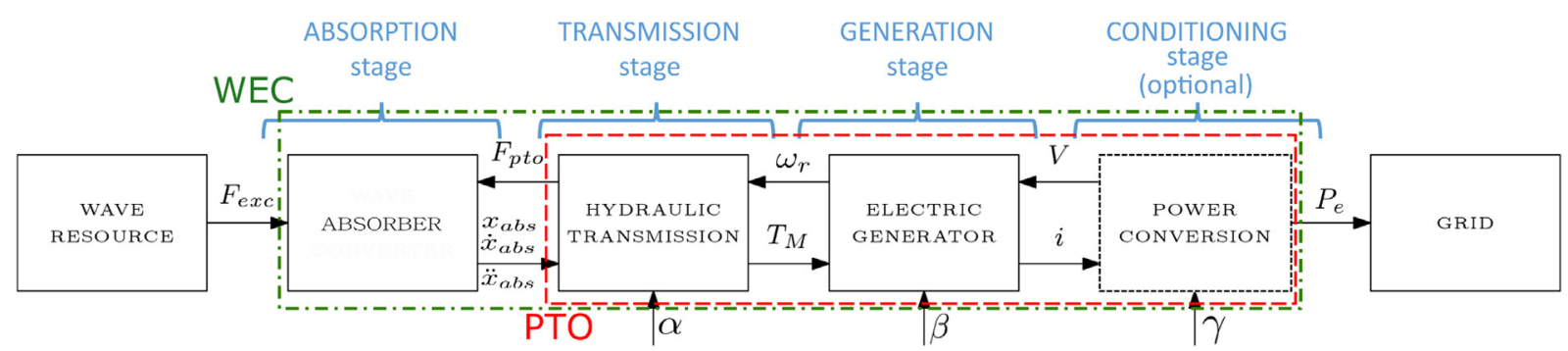

Fig. 1. Diagram of a wave energy converter with a hydraulic power take-off, including potential control inputs.

including overtopping converters [3], oscillating water columns (OWCs) [4,5], and wave-activated converters with different PTO systems, such as hydraulic [6-11], mechanical [12,13], magnetic [14], or linear generators $[15,16]$. The open-source code WEC-Sim implemented in Matlab/Simulink also provides W2W models for different wave energy devices and PTO systems [17,18].

Wave-absorber hydrodynamic interaction in W2W models is usually modelled using a linear method, with a few published exceptions including nonlinear Froude-Krylov (FK) forces [11,17] or viscous effects [5,10]. PTO models with hydraulic transmission systems implemented in W2W models often use significant simplifications. More sophisticated hydraulic PTO models in the literature include fluid compressibility [6], non-ideal efficiency for the hydraulic motor [9], dynamic motor losses [10], or constant nonideal efficiency in the cylinder and dynamic losses in the motor [8]. Finally, electric generators in W2W models are often modelled using a constant torque and/or constant non-ideal efficiency coefficient. Electrical dynamics of rotary generators are considered in Refs. [9,11,13] and power converters are only included in Ref. [13] for rotary generators and in Ref. [16] for linear generators. Further details of the existing W2W models can be found in Ref. [2].

Although some W2W models provide great detail for specific conversion stages, to date and to the best knowledge of the authors, none of the existing W2W models in the literature captures all the necessary features of all the conversion stages to accurately evaluate the holistic performance of a WEC. The W2W model presented in this paper includes four unique characteristics:

- The model is generic, in the sense it can, with appropriate modification, accommodate different

- types of absorbers with one or multiple degrees of freedom (DoFs), single- or multi-body absorbers, or even an array of absorbers

- rotational electric generators, fixed- or variable speed generators; and

- grid connections, i.e. directly connected or through a back-toback (B2B) configuration.

- The model provides high-fidelity results, incorporating precise models for each conversion stage, considering nonlinear dynamics, constraints and energy losses, and articulating control inputs.

- The model has been validated against high-fidelity software or experimental results.

- The model is computationally efficient, mitigating its high computational requirements by utilising multi-rate time-integration schemes.

This high-fidelity W2W model is crucial to assess the commercial viability of WECs and make the correct decisions in the development pathway towards economically successful WECs. In fact, one of the main issues in the development of WECs is the high investments required to demonstrate the suitability of the concept and gain confidence on the technology through expensive prototype demonstrations. Commercial viability of a WEC can be quantified via the technology performance level (TPL) and technology readiness level (TRL) suggested in Ref. [19], where TRL is mainly related to the required investment and the TPL to the cost of energy. Hence, the ideal development trajectory suggested in Ref. [19] recommends improving the TPL at low TRLs, as illustrated in Fig. 2, delaying the expensive experiments until a high confidence is gained on the technology. Therefore, high-fidelity W2W models are crucial to thoroughly evaluate the performance of a WEC at low TRLs, before engaging in expensive demonstration stages.

The remainder of the paper is organised as follows: Section 2 presents the equations of the W2W model, including the hydrodynamic model, the hydraulic transmission systems for cons $P$ and varP PTO configurations, the electric generator and power converters, Section 3 describes the implementation of the W2W model using single-rate (SR) and multi-rate (MR) time-integration schemes and a comparative study to find the most efficient integration method, Section 4 presents results obtained using the W2W model described in the paper with two different hydraulic PTO configurations, and conclusions are drawn in Section 5.

\section{High-fidelity wave-to-wire model}

The W2W model is designed as a combination of interconnected sub-models, as illustrated in Fig. 1. Any perturbation in any of the subsystems has an impact on the preceding and/or following sub-models due to the bi-directional interconnections.

The first subsystem, the wave resource, generates the primary input for the W2W model. This input is the water free-surface elevation time-series $\left(\eta_{w}\right)$, generated for the whole simulation time prior to running the simulation. The most established method to generate polychromatic free-surface elevation time-series, assuming unidirectional waves and $\eta_{w}$ measurements at the centre of the absorber, is by adding a finite number of sinusoidal Fourier components as follows [20],

$\eta_{w}\left(t_{i}\right)=\sum_{k=1}^{N} A_{k} \cos \left(2 \pi f_{k} t\left(t_{i}\right)+\phi_{k}\right)$

where $N$ is the number of frequency components, $f_{k}$ the frequency in $\mathrm{Hz}, \phi_{k} \in[0,2 \pi]$ the randomly chosen phase, $A_{k}=\sqrt{2 S\left(f_{k}\right) \Delta f}$ the amplitude function, $S\left(f_{k}\right)$ is the spectral density function that represents wave characteristics of a given location, and $\Delta f$ is the frequency step.

\subsection{Hydrodynamic model}

The excitation force, calculated from the free-surface elevation 


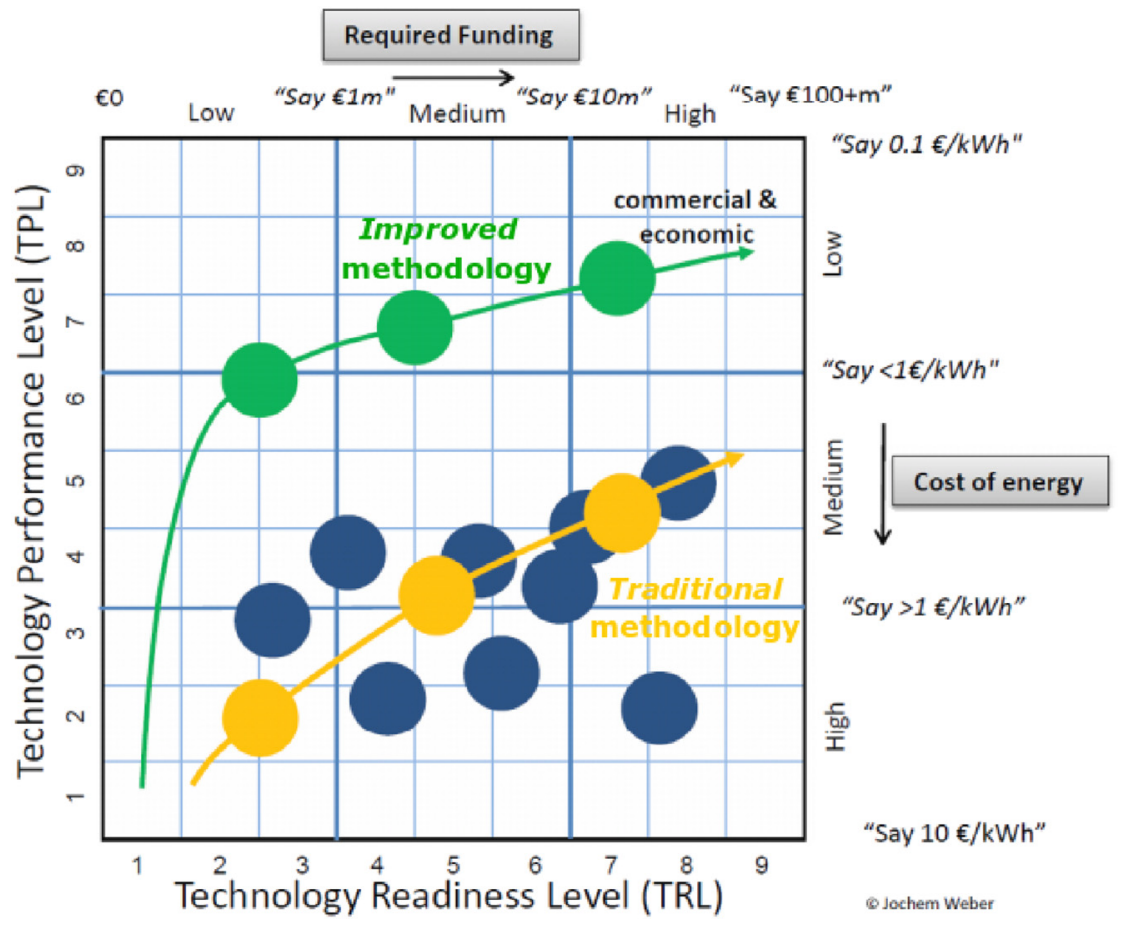

Fig. 2. WEC development trajectories suggested in Ref. [19].

and the device characteristics, is the principal input to the hydrodynamic model at the absorption stage. The output of the timedomain hydrodynamic model is the motion of the absorber as a response to the ocean waves and the $\mathbf{F}_{\text {PTO }}$ from the transmission stage. The hydrodynamic model includes nonlinear FK force $\left(\mathbf{F}_{\mathbf{F K}}\right)$ and viscous effects $\left(\mathbf{F}_{v i s c}\right)$, which have been identified as the most important nonlinear effects for point abosrbers (PAs) and oscillating wave surge converters (OSWCs) [21].

To consider nonlinear FK forces, the excitation force is divided into dynamic FK and diffraction forces. Hence, the wave pressure $\left(\mathbf{p}_{\mathbf{I}}\right)$, including static $\left(\mathbf{p}_{I_{\text {stat }}}\right)$ and dynamic $\left(\mathbf{p}_{I_{d y n}}\right)$ components, is computed over the instantaneous wetted-surface of the device using a computationally efficient algebraic method [22], which can be implemented for axisymmetric PAs and OSWC [23], including multiple-DoFs devices [24].

The time-domain hydrodynamic model, based on Cummins' equation [25], is given as follows,

$$
\begin{aligned}
\mathbf{M} \ddot{\mathbf{x}}_{a b s}(t)= & \mathbf{F}_{g}+\mathbf{F}_{F K}(t)+\int_{-\infty}^{\infty} \mathbf{K}_{d i f f}(t-\tau) \eta_{w}(\tau) d \tau-\boldsymbol{\mu}_{\infty} \ddot{\mathbf{x}}_{a b s}(t) \\
& -\int_{-\infty}^{t} \mathbf{K}_{r a d}(t-\tau) \dot{\mathbf{x}}_{a b s}(\tau) d \tau+\mathbf{F}_{P T O}+\mathbf{F}_{v i s c}
\end{aligned}
$$

where $\mathbf{M} \in \mathbb{R}^{n \times n}$ is the mass matrix of the absorber, $n$ the number of DoFs, and $\mathbf{F}_{g} \in \mathbb{R}^{n}$ the gravity force vector. $\mathbf{K}_{\text {diff }} \in \mathbb{R}^{n \times n}$ is the diffraction impulse response function (IRF) matrix, $\mu_{\infty} \in \mathbb{R}^{n \times n}$ the added-mass matrix at infinite frequency, and $\mathbf{K}_{\text {rad }} \in \mathbb{R}^{n \times n}$ the radiation IRF matrix. Hydrodynamic coefficients in frequency-domain, required to calculate the IRFs and $\mu_{\infty}$, are obtained using the open-source boundary element method code NEMOH [26].

Nonlinear $\mathbf{F}_{F K} \in \mathbb{R}^{n}$, including the static and dynamic FK force, is given [22] as follows,

$$
\begin{aligned}
\mathbf{F}_{F K} & =\iint_{S(t)}\left(\mathbf{p}_{I_{\text {stat }}}+\mathbf{p}_{I_{d y n}}\right) d S \\
& =\int_{0}^{2 \pi} \int_{\sigma_{1}}^{\sigma_{2}} \mathbf{p}_{I}(x(\sigma, \theta), z(\sigma, \theta), t) f \prime(\sigma) f(\sigma) d \sigma d \theta
\end{aligned}
$$

where $S(t)$ is the instantaneous wetted-surface, and $x$ and $z$ the Cartesian coordinates. In the case of heave motion, the integration limits that define $S(t)$ are $\sigma_{1}=z_{d}-H$ and $\sigma_{2}=\eta_{w}$, where $\mathrm{H}$ is the draft of the device, and $\sigma$ and $\theta$ the parametric cylindrical coordinates of the algebraic solution. The pressure $p_{I}$ integrated over the instantaneous wetted-surface is defined via the linear representation, which is demonstrated to be accurate enough for representation in the power production region [27]. Note that the nonlinear restoring force is considered in Equation (2), given by the sum of $\mathbf{F}_{g}$ and the static component of $\mathbf{F}_{F K}$ in Equation (3).

Finally, viscous effects are modelled using a Morison-like equation [28],

$\mathbf{F}_{v i s c}=-\frac{1}{2} \rho \mathbf{C}_{d r a g} \mathbf{A}_{d}(t)\left|\dot{\mathbf{x}}_{a b s}-\mathbf{V}_{\mathbf{0}}\right|\left(\dot{\mathbf{x}}_{a b s}-\mathbf{V}_{\mathbf{0}}\right)$

where $\rho$ is the density of water, $\mathbf{C}_{d r a g}$ and $\mathbf{A}_{d} \in \mathbb{R}^{n \times n}$ the positive constant diagonal matrices describing the drag coefficient and the instantaneous cross-sectional area of the device, respectively, and $\mathbf{V}_{\mathbf{0}} \in \mathbb{R}^{n}$ the velocity vector of the undisturbed water particles.

The hydrodynamic model is validated against computational fluid dynamics (CFD) simulations in Ref. [29], where a heaving PA is examined when moving with and without control. When control is implemented, nonlinear modelling of FK forces and viscous effects become particularly relevant [27]. 


\subsection{Hydraulic transmission system}

Hydraulic transmission systems can transform the reciprocating motion of an absorber into unidirectional rotation for an electrical generator. Example devices using such a PTO include Pelamis [30], Searev [6], Wavestar [31], Oyster [32], CETO [33] or Waveroller [34].

Hydraulic PTO systems can be organised into two main categories: consP, e.g. in Fig. 3 (a), and varP, e.g. in Fig. 3 (b), PTO configurations.

Constant-pressure PTO configurations have been suggested in Refs. [6,7,11], among others, and use large volume low- and highpressure accumulators and a rectification bridge to provide a smooth output torque to the hydraulic motor. The hydraulic efficiency of consP hydraulic PTO systems is, in general, reasonably high, since the hydraulic motor can be controlled to operate close to the optimal operating point most of the time. However, the highpressure accumulator included between the cylinder and the hydraulic motor limits the possibility of actively controlling the absorber via the hydraulic motor, since variations in the hydraulic motor displacement take a long time to affect the behaviour of the absorber.

In contrast, varP PTO configurations, implemented in Refs. [8,35], are more flexible, since the hydraulic cylinder is directly connected to the hydraulic motor, without any highpressure accumulator in between. Hence, variations in the hydraulic motor displacement rapidly affect the behaviour of the hydraulic cylinder and, as a consequence, the absorber motion, permitting the active control to maximise power absorption.

The vector of PTO forces is given as $\mathbf{F}_{\text {PTO }}=\mathbf{F}_{C} F_{\text {PTO }}$, where $\mathbf{F}_{c} \in \mathbb{R}^{n \times m}$ is a constant matrix known as configuration matrix, that allows the combination of different oscillation models to absorb energy [36]. The number of PTO forces $(m)$ is, in general, lower than the number of oscillation modes $(m<n)$. The PTO force applied from the hydraulic cylinder can be calculated as follows,

$F_{\text {PTO }}=A_{p}\left(p_{B}-p_{A}\right)+F_{\text {fric }}+F_{\text {in }}$

where $A_{p}$ is the piston area, $p_{A}$ and $p_{B}$ are the pressure in chambers $\mathrm{A}$ and $\mathrm{B}$ of the hydraulic cylinder, respectively, and $F_{\text {fric }}$ and $F_{\text {in }}$ are friction and inertia forces in the cylinder. Pressure dynamics in cylinder chambers, including compressibility effects, are modelled using the continuity equation, $\dot{p}=\frac{\beta_{\text {eff }}}{V+A_{p} x_{p}}\left(Q-\dot{x}_{p} A_{p}\right)$

where $x_{p}$ and $\dot{x}_{p}$ are the piston position and velocity, $Q$ is the flow entering or exiting the cylinder chamber, $\beta_{\text {eff }}$ the effective bulk modulus and $V$ the minimum volume (calculated when the piston reaches its minimum or maximum position) in the cylinder chamber.

Friction in the cylinder is modelled using the Stribeck model, which includes viscous, Coulomb and static friction [37], and the inertia force considers the inertial contribution of the cylinder piston $\left(M_{p}\right)$, rod $\left(M_{r}\right)$ and oil $\left(M_{o i l}\right)$ due to the piston acceleration,

$F_{\text {fric }}=\sigma_{v} \dot{x}_{p}+\operatorname{sign}\left(\dot{x}_{p}\right)\left[F_{c}+F_{s t} \exp \left(-\frac{\left|\dot{x}_{p}\right|}{c_{s t}}\right)\right]$

$F_{\text {in }}=\ddot{x}_{p}\left(M_{p}+M_{r}+M_{\text {oil }}\right)$

where $\sigma_{v}$ is the viscous coefficient, $F_{c}$ the Coulomb friction force, $F_{s t}$ the static friction force, $c_{s t}$ the characteristic velocity of the Stribeck curve, and $\ddot{x}_{p}$ the piston acceleration.

In the case of the consP configuration, the rectification bridge is, in general, composed of passive check valves that open and close as a function of the pressure difference across the valve. The flow across the valve can be modelled using the orifice equation [37],

$Q_{v}=C_{d} A_{v}(\Delta p) \operatorname{sign}(\Delta p) \sqrt{\frac{2}{\rho_{\text {oil }}}|\Delta p|}$

where $Q_{v}$ is the flow through the valve, $C_{d}$ the discharge coefficient, $A_{v}(\Delta p)$ the valve opening area as a function of the pressure difference across the valve and $\rho_{\text {oil }}$ the density of the hydraulic oil.

Accumulators are also a key component of the consP hydraulic PTO systems, which are, in general, gas filled. The gas compression and expansion process can be described by means of an isentropic and adiabatic process, for which the pressure in the accumulator is given as,

$p_{a c c}=p_{\text {pre }}\left(\frac{V_{\text {tot }}}{V_{\text {gas }}}\right)^{\gamma}$

where $V_{\text {tot }}$ is the total volume of the accumulator, $V_{\text {gas }}$ the gas volume in the accumulator, $p_{\text {pre }}$ the pre-charged pressure of the

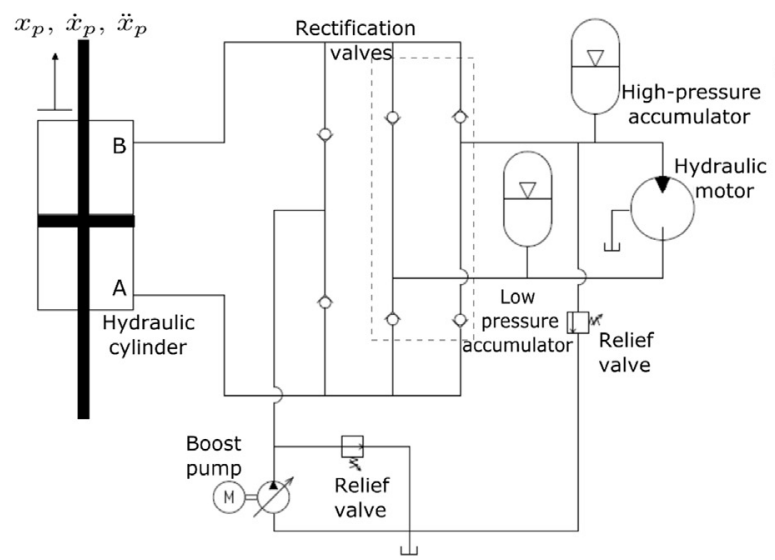

(a)

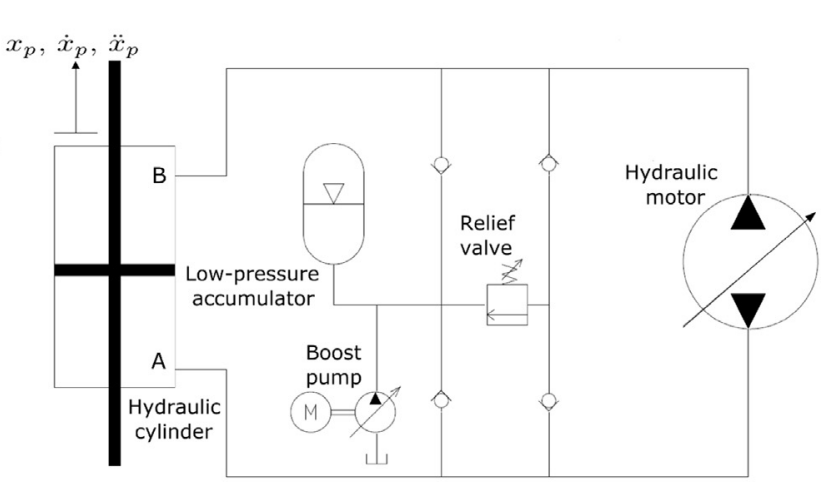

(b)

Fig. 3. Typical constant- (a) and variable-pressure (b) configurations. 
accumulator, and $\gamma$ the adiabatic index for an ideal gas.

Hydraulic motors are the final component of all hydraulic PTO systems, where modelling volumetric and mechanical losses must be considered. The Schlösser loss model $[38,39]$ includes losses in the motor due to friction and leakages, so the output flow $\left(Q_{M}\right)$ and $T_{M}$ can be described as follows,

$Q_{M}=u D_{\omega} \omega_{M}-\Delta p_{M} C_{Q 1}$

$T_{M}=u D_{\omega} \Delta p_{M}-\left(C_{T 1}+C_{T 2} \Delta p_{M}+C_{T 3} \omega_{M}+C_{T 4} \omega_{M}^{2}\right)$

where $u$ is the motor displacement fraction, $D_{\omega}$ the displacement of the hydraulic motor, $\omega_{M}$ the rotational speed of the shaft, $\Delta p_{M}$ the pressure difference across the hydraulic motor, and $C_{Q 1}, C_{T 1}, C_{T 2}$, $C_{T 3}$ and $C_{T 4}$ the parameters of the Schösser loss model. The hydraulic motor displacement fraction $u$ can take any value between $[-1,1]$ and is determined based on the desired pressure difference in the hydraulic cylinder, $u=f\left(\Delta p^{*}\right)$, which is, in turn, defined by the reference PTO force $\left(F_{P T O}^{*}\right)$,

$\Delta p^{*}=\frac{F_{P T O}^{*}}{A_{p}}$

Further details of the hydraulic transmission model, such as the identification of the parameters of the Stribeck friction model or Schösser loss model, are provided in Ref. [40], where the mathematical models for consP and varP hydraulic PTO systems are validated against experimental data.

Additional validation of the mathematical model for the hydraulic cylinder is carried out with experimental data from a hardware-in-the-loop (HIL) test rig, kindly provided by Swirl Generators Limited (SGL), where a simulation model that emulates the motion of a two-body heaving PA is coupled to a real hydraulic cylinder that emulates a varP hydraulic PTO system [41]. Fig. 4 illustrates that validation, where PTO force results from the HIL simulation and the mathematical model show excellent agreement.

\subsection{Electric generator and power converter system}

Electric generators can be either connected directly to the electricity grid, in which case no conditioning stage is required, or in a B2B configuration, using power converters. Directly connected generators operate at a fixed-speed dictated by the electricity network, while variable-speed generators, grid connected in a B2B configuration, provide a greater flexibility for adapting to different operating conditions.

Different electric generators have been suggested in the literature as part of a WEC PTO system, e.g. the squirrel-cage induction generator (SCIG) [8], the doubly-fed induction generator (DFIG) [4] or the permanent magnet synchronous generator (PMSG) [42]. All three generators can be used in the W2W model, but only the models for the SCIG and the DFIG, which are almost identical, are described in this section due to lack of space. Using the equivalent two-phase $(d q)$ equations, a mathematical model of the DFIG can be given as follows [43],

$V_{s d}=R_{s} i_{s d}-\omega \lambda_{s q}+L_{s} \frac{d}{d t} i_{s d}+L_{m} \frac{d}{d t}\left(i_{s d}+i_{r d}\right)$

$V_{s q}=R_{s} i_{s q}+\omega \lambda_{s d}+L_{s} \frac{d}{d t} i_{s q}+L_{m} \frac{d}{d t}\left(i_{s q}+i_{r q}\right)$

$V_{r d}=R_{r} i_{r d}-\left(\omega-\omega_{r}\right) \lambda_{r q}+L_{r} \frac{d}{d t} i_{r d}+L_{m} \frac{d}{d t}\left(i_{s d}+i_{r d}\right)$

$V_{r q}=R_{r} i_{r q}+\left(\omega-\omega_{r}\right) \lambda_{r d}+L_{r} \frac{d}{d t} i_{r q}+L_{m} \frac{d}{d t}\left(i_{s q}+i_{r q}\right)$

where $R$ is the resistance and $\lambda$ the flux linkage. Subscripts $s$ and $r$ are used for the stator and rotor, while $d$ and $q$ refer to the direct and quadrature axes, respectively. $\omega$ and $\omega_{r}$ are the angular speed of the reference frame and the rotor, respectively. The model for the SCIG can be obtained by setting $V_{r d}=V_{r q}=0$ in Equations (16) and (17). The flux linkage expressions, as a function of currents, are,

$\lambda_{s d}=\left(L_{s}+L_{m}\right) i_{s d}+L_{m} i_{r d}$

$\lambda_{s q}=\left(L_{s}+L_{m}\right) i_{s q}+L_{m} i_{r q}$

$\lambda_{r d}=\left(L_{r}+L_{m}\right) i_{r d}+L_{m} i_{s d}$

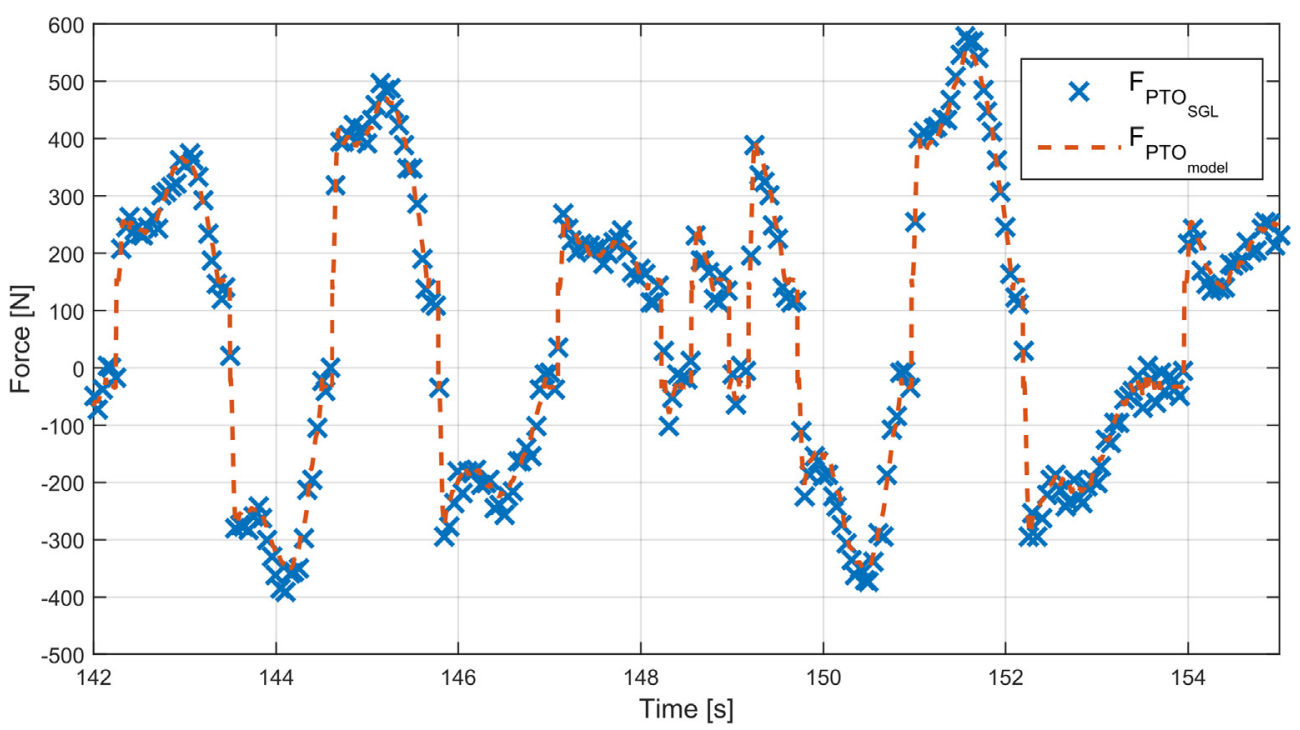

Fig. 4. Hydraulic cylinder force, emulating a varP hydraulic PTO system, for the experimental and numerical results. Validation data was kindly provided by SGL. 
$\lambda_{r q}=\left(L_{r}+L_{m}\right) i_{r q}+L_{m} i_{s q}$

where $L_{S}$ and $L_{r}$ are the stator and rotor leakage inductances, respectively, and $L_{m}$ is the mutual inductance.

Hence, the electromagnetic torque developed in induction machines can be given by

$T_{e}=\frac{3 N_{p}}{4}\left(\lambda_{s d} i_{s q}-\lambda_{s q} i_{s d}\right)$

where $N_{p}$ is the number of poles in the generator. The mechanical equation for the acceleration of the generator shaft is

$\dot{\omega}_{r}=\frac{N_{p}}{2 J}\left(T_{e}-T_{M}-B_{\text {wind }} \omega_{r}\right)$

where $B_{\text {wind }}$ is the friction/windage damping and $J$ the inertia moment of the generator shaft. Parameters $R_{r}, R_{s}, L_{r}, L_{s}, L_{m}, N_{p}$,J and $B_{\text {wind }}$ vary depending on the type and rating of the generator, and can be obtained from the literature or identified experimentally.

Generated active $\left(P_{e}\right)$ and reactive power $\left(Q_{e}\right)$, identical for induction and permanent magnet generators, can be calculated as,

$P_{e}=\frac{3}{2}\left(V_{s d} i_{s d}+V_{s q} i_{s q}\right)$

$Q_{e}=\frac{3}{2}\left(V_{s q} i_{s d}-V_{s d} i_{s q}\right)$

Further details of the mathematical models for the three generators and the validation of the models against experimental results can be found in Ref. [44]. Fig. 5 illustrates the trend line of the efficiency curve as a function of normalised rotational speed for the SCIG, showing a good agreement between experimental results and results from the mathematical model. The rotational speed is normalised against the synchronous speed, which in this case is $1500 \mathrm{rpm}$.

The effect of the inverters in a B2B power converter is also validated in Ref. [44], where inverters are employed to control the rotational speed in the generators and the voltage in the DC-link of the B2B power converter. The switching operations of power

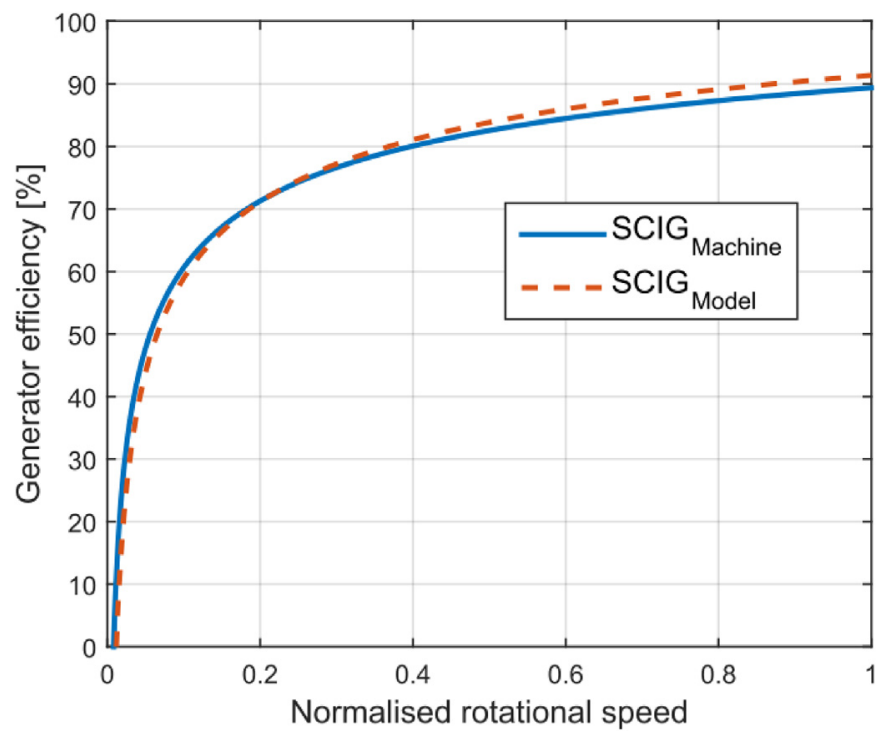

Fig. 5. Trend lines of the efficiency curves obtained from the real machine and the mathematical model for the SCIG. switches in the inverters operate well beyond the bandwidth of other components, and are neglected. Power losses in the inverter are included by means of an efficiency curve fitted using experimental data [44], which is consistent with other curves shown in the literature, for example in Ref. [45].

The grid connection of the consP and varP hydraulic PTO configurations, defined in Section 2.2, is usually different in the literature. Due to the smooth power output provided by the consP configurations, the electric generator is, in general, directly connected to the electricity grid. In contrast, the highly varying power output signal provided by the varP hydraulic PTO configurations suggests that inverters are required to fulfil the restrictions imposed by the electricity grid.

\section{Model implementation}

The W2W model is implemented as a fixed-step simulation model in Matlab, where the different conversion stages are coded as interconnected sub-models, as illustrated in Fig. 1. Hence, W2W models with different components, i.e. different absorbers, hydraulic PTO configurations, electric generators or grid connections, can be easily accommodated.

\subsection{Single-rate solver}

Due to the different dynamics of the components which make up a W2W model, different sample periods are required to accurately reproduce the behaviour of the components described in each sub-model. For example, a sample period of $10 \mathrm{~ms}$ is suitable for wave-absorber interactions, while a period of $1 \mathrm{~ms}$ is recommended for hydraulic PTO systems [40], and a period of $50 \mu$ s for electrical generators [44]. The sample period of $1 \mathrm{~ms}$ for hydraulic PTO systems may need to be adjusted to consider fast dynamics, such as valve opening and closing. Therefore, when a SR solver is implemented, the shortest sample period ( $50 \mu \mathrm{s}$, in this case) is necessary to capture the dynamics of the fastest components. This requirement adds unnecessary computations for the components with slower dynamics and dramatically increases the simulation time and memory requirements.

\subsection{Multi-rate solver}

Multi-rate time-integration schemes permit the implementation of different sampling periods in different components. Thus, longer sampling periods can be implemented in components with slower dynamics, avoiding unnecessary computations [46,47]. Submodels with different sampling periods are connected by performing appropriate up-sampling and down-sampling on the output signals from each subsystem.

Up- and down-sampling are performed by interpolating the signals (interpolation is required in down-sampling only when the time-steps of the interconnected sub-models are not multiples of each other), for which different interpolation methods, such as linear, cubic or spline, have been investigated. Identical results have been obtained for the different methods, which suggests that a linear interpolation is the most suitable, also having appealing computational requirements.

A fourth order Runge-Kutta (RK) solver is initially employed to compare MR simulation results against SR results evaluating computational requirements and the fidelity of the output variables in the three main sub-models: hydrodynamic sub-model (HdM), hydraulic sub-model (HyM) and electric sub-model (ElecM). The deviation between the results obtained with the SR and MR simulation models is calculated by means of the normalised root mean square deviation (NRMSD) as follows, 
$N R M S D=\frac{\sqrt{\frac{\sum_{k=1}^{n}(y(k)-\widehat{y}(k))^{2}}{n}}}{\bar{y}}$

where $y$ and $\hat{y}$ represent the variables obtained from the SR and MR models, respectively, $n$ is the length of the variables and $\bar{y}$ represents the mean of the variable $y$. Thus, the NRMSD is bounded between 0 and 1 , and can be used to calculate the fidelity of the variables obtained from the MR model compared to the SR model expressed in percentage as follows,

Fidelity $=(1-N R M S D) \times 100[\%]$

Position and velocity of the absorber are evaluated in HdM. Cylinder pressure difference and force, and motor flow and torque are studied in HyM. Finally, current, voltage, active power and rotational speed are analysed in ElecM. The fidelity of a sub-model is calculated as the mean of the fidelities for all sub-model variables. Fidelity values, illustrated in Fig. 6, exceed 99.5\% with the deterioration attributed to the interpolation of the signals in upand down-sampling.

With respect to computational requirements, simulation time is reduced by a factor of 5 in the MR simulation compared to the SR simulation, where all interpolation calculations represent less than $0.05 \%$ of the total simulation time.

The RK4 integration method is, in the experience of the authors, the most commonly implemented method in simulation models for wave energy applications, though little justification is offered, to the best knowledge of the authors. Therefore, a comparative study was carried out in this paper to find the most efficient integration method, comparing different iterative and multi-step explicit and implicit methods: explicit RK [48], explicit Adams-Bashforth (AB) [49], implicit Adams-Moulton (AM) [49] and implicit backward differentiation function (BDF) [50] of orders between 2 and 4 . The conventional $\mathrm{RK}, \mathrm{AB}, \mathrm{AM}$ and $\mathrm{BDF}$ integration schemes are used in this paper, for which the second-order representations are described in Equations (28)-(31), respectively. It should be noted that the implicit AM and BDF methods are used in tandem with the $A B$ method as a predictor-corrector pair, to solve the implicit equation.

$y_{n+1}=y_{n}+h f\left(t_{n}+\frac{1}{2} h, y_{n}+\frac{1}{2} h f\left(t_{n}, y_{n}\right)\right)$
$y_{n+1}=y_{n}+h\left(\frac{3}{2} f\left(t_{n}, y_{n}\right)-\frac{1}{2} f\left(t_{n-1}, y_{n-1}\right)\right)$

$y_{n+1}=y_{n}+\frac{1}{2} h\left(f\left(t_{n+1}, y_{n+1}\right)+f\left(t_{n}, y_{n}\right)\right)$

$y_{n+1}=\frac{4}{3} y_{n}-\frac{1}{3} y_{n-1}+\frac{2}{3} h f\left(t_{n+1}, y_{n+1}\right)$

where $y_{n}$ is the present value at $t_{n}, y_{n+1}$ the approximation of $y\left(t_{n+1}\right), h$ the step length and $f\left(t_{n}, y_{n}\right)$ the derivative of $y_{n}$.

Results from higher order methods, such as 5th order DormandPrince, are identical to the results from RK4 for all the variables. Therefore, the SR-RK4 method is considered as a benchmark.

An extra complication may appear when modelling hydraulic PTO systems. Hydraulic systems are stiff systems due to the fast compressibility of the hydraulic fluid combined with the other relatively slow dynamics. Fig. 7(a) and (b) illustrate the motion of the device and the pressure in the hydraulic cylinder, respectively, using the second order RK solver for the first 30s and the secondorder $A B$ solver for the last 30 s. Both solvers are numerically stable for the hydrodynamic model, as shown in Fig. 7 (a), while instability issues are evident in the last $30 \mathrm{~s}$ of the hydraulic PTO simulations, as illustrated in Fig. 7 (b), where instabilities are highlighted in the zoomed dashed circle. Likewise, AM and BDF solvers of order greater than two show stability problems when
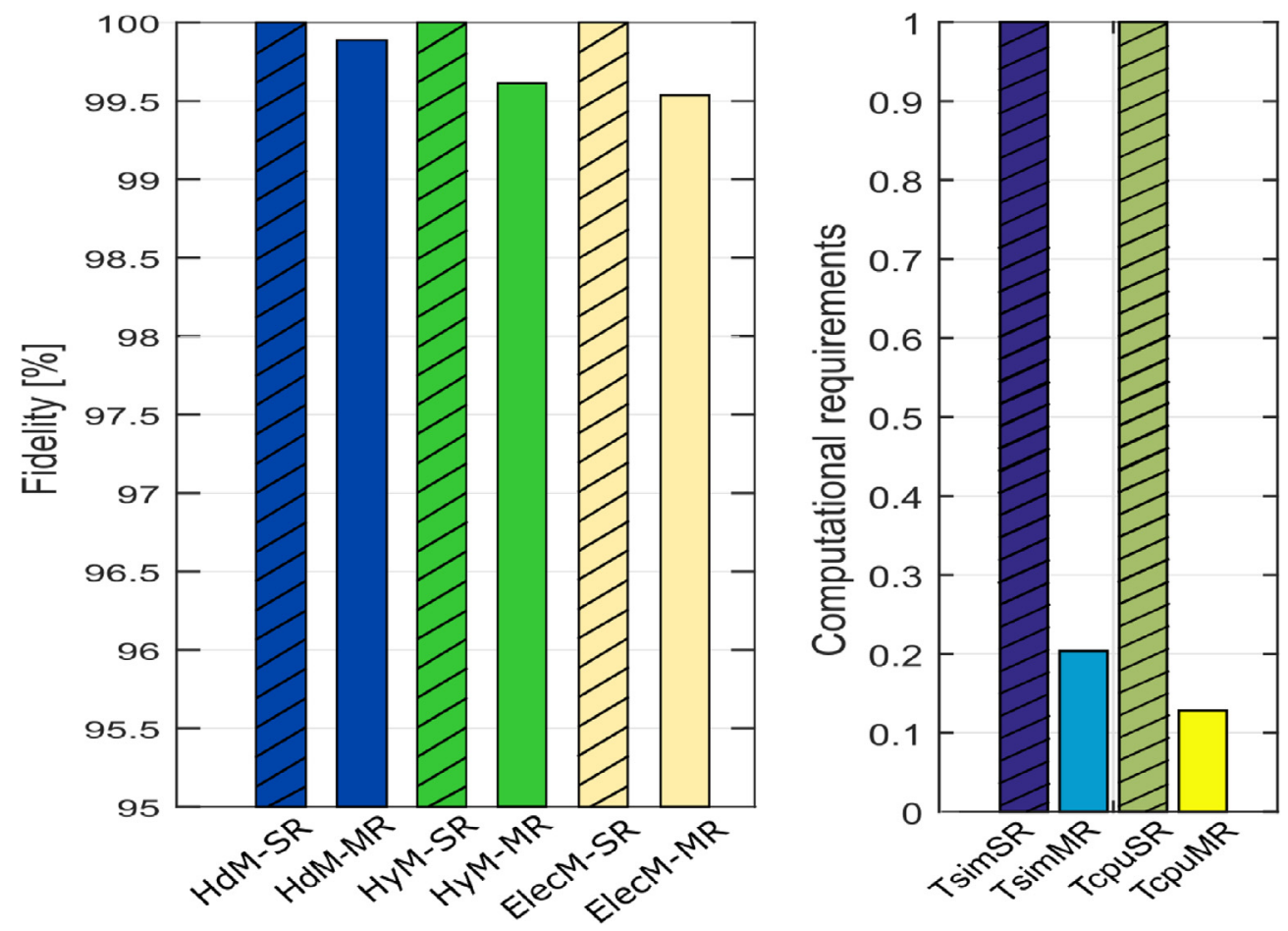

Fig. 6. Fidelity and computational requirement characteristics of the SR and MR schemes using the RK4 method. 
(a)

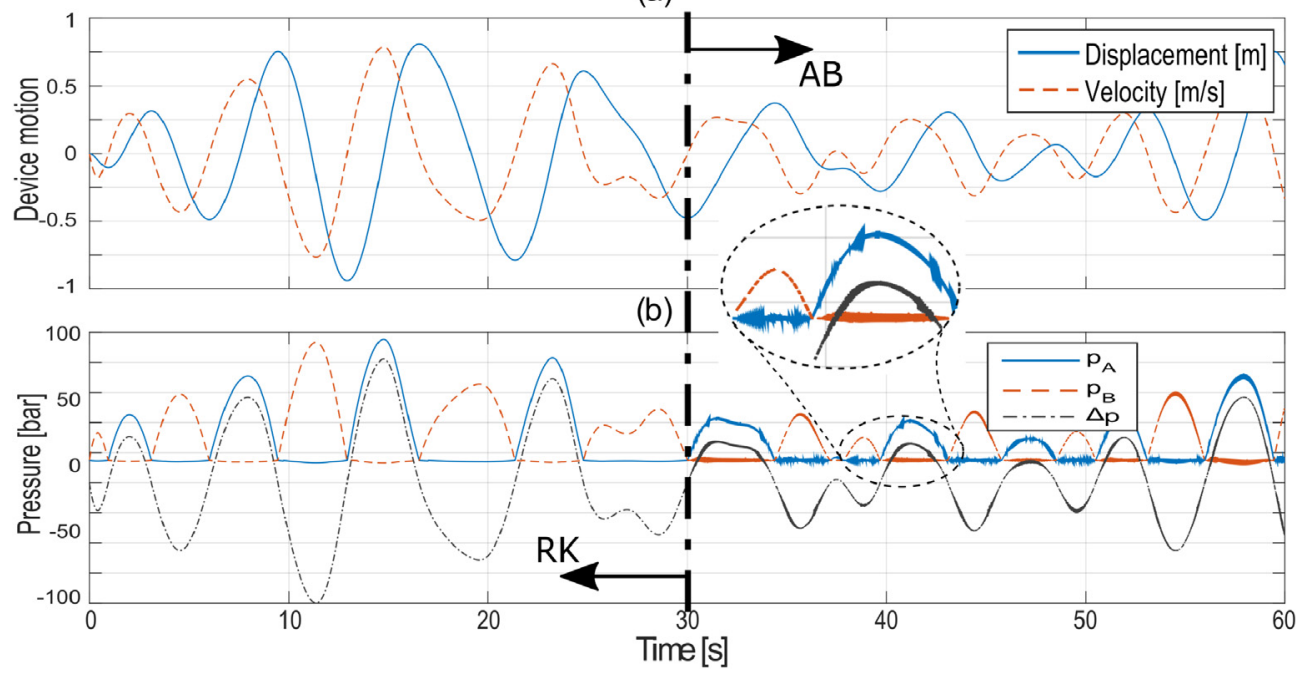

Fig. 7. Hydrodynamic (a) and hydraulic subsystem (b) results for the RK and AB methods.

modelling the hydraulic PTO, unless the sampling rate is significantly increased [51]. Consequently, AB methods of all orders and $\mathrm{AM}$ and BDF methods of order greater than two are directly discarded from the comparative study.

Hence, RK methods of order two, three and four, and AM and BDF methods of order two are analysed in terms of accuracy and computational requirements, taking the SR-RK4 method as the benchmark. Fig. 8 shows the fidelity values of each integration method for the different sub-models against the normalised computational time, where the colour code refers to the different sub-models corresponding to the colour code used in Fig. 6. As expected, second-order methods have the most appealing computational features, while higher-order RK methods are more accurate. However, RK2 exhibits appealing computational characteristics of the second-order methods and the accuracy of higherorder methods. Nevertheless, high-order RK methods could theoretically use larger time-steps than low-order RK methods, while providing similar fidelity levels. Therefore, to provide a fair comparison between high- and low order RK methods, a RK4 with a larger time-step (RK4a) is also included in the comparison. The time-steps for RK4a are defined so that computational requirements for RK2 and RK4a are similar: $20 \mathrm{~ms}, 2 \mathrm{~ms}$ and $75 \mu \mathrm{s}$ for the HdM, HyM and ElecM, respectively. Fig. 8 shows that, compared to RK2, RK4a provides identical fidelity for $H d M$, but lower fidelity

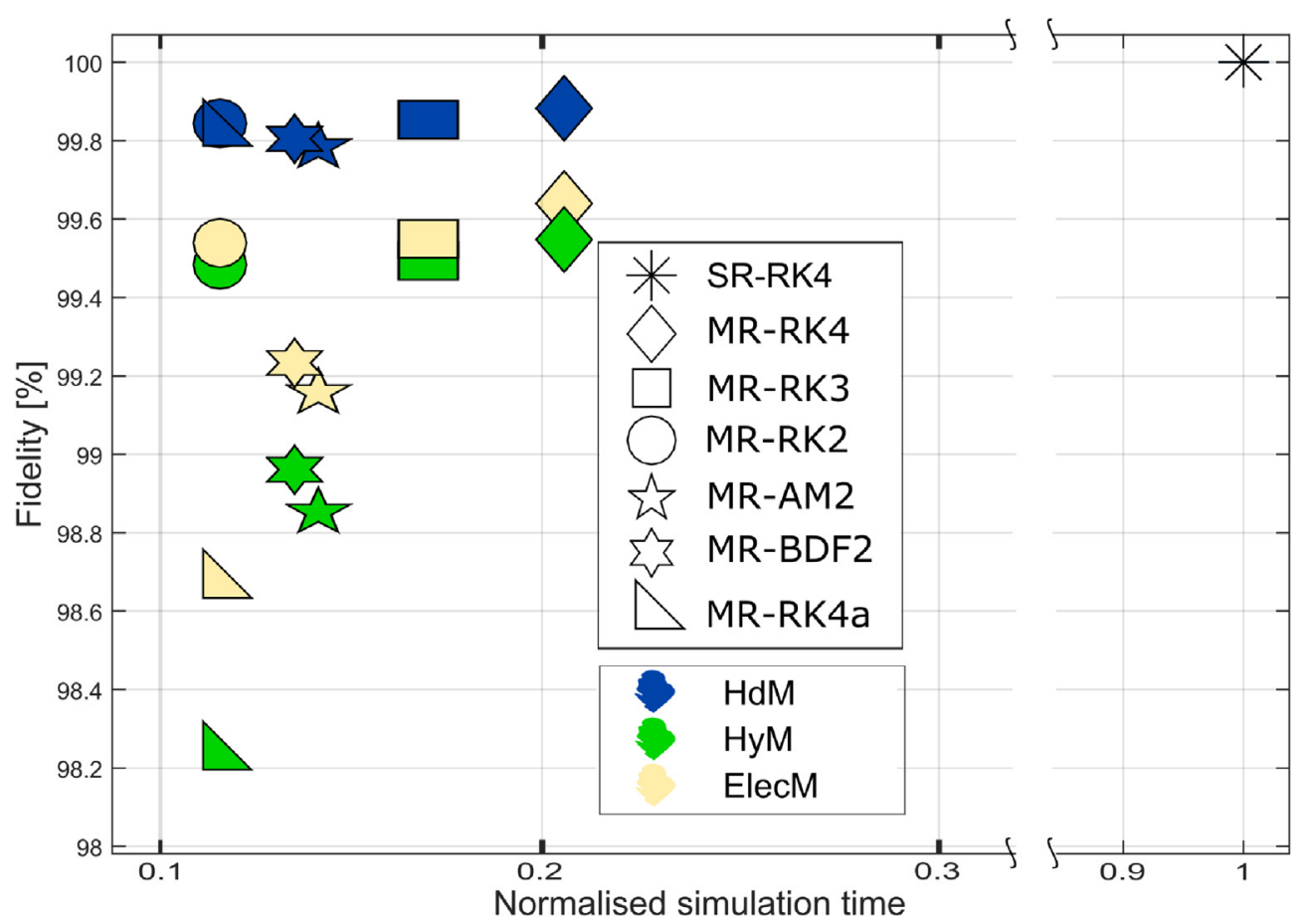

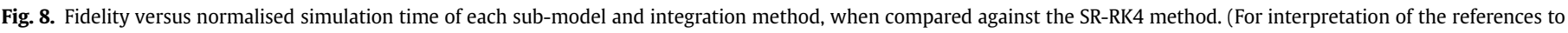
colour in this figure, the reader is referred to the web version of this article.). 
for HyM and, particularly, ElecM. In addition, stability issues appear in HyM when using RK4a, due to the implemented larger timesteps.

As a consequence, RK2 is demonstrated to be the most efficient method, providing almost indistinguishable results when compared to the results obtained using the SR-RK4 method, while requiring approximately a tenth of the time taken by SR-RK4.

However, in the event that the hydraulic PTO systems are modified so as to include more compression/expansion processes, a higher-order integration method may be necessary to accurately reproduce the more complex dynamics of such a hydraulic PTO system [31]. In such a case, the rest of the sub-models could still use the RK2 method, resulting in a multi-rate multi-solver W2W model.

\section{Results}

The holistic performance of a spherical PA restricted to move only in heave, with consP and varP hydraulic PTO systems is analysed using the W2W model presented in Section 2. Fig. 9 illustrates the schematic of the spherical heaving PA. The input free-surface elevation time-series is based on a JONSWAP spectrum of a $1.5 \mathrm{~m}$ significant wave height and a 9s peak period. Due to the fundamental differences between consP and varP hydraulic PTO configurations, an identical hydraulic cylinder is used in both configurations, and the control forces used in both configurations are similar in magnitude, in order to provide a fair comparison. That way, the force applied on the spherical heaving PA is also similar, at

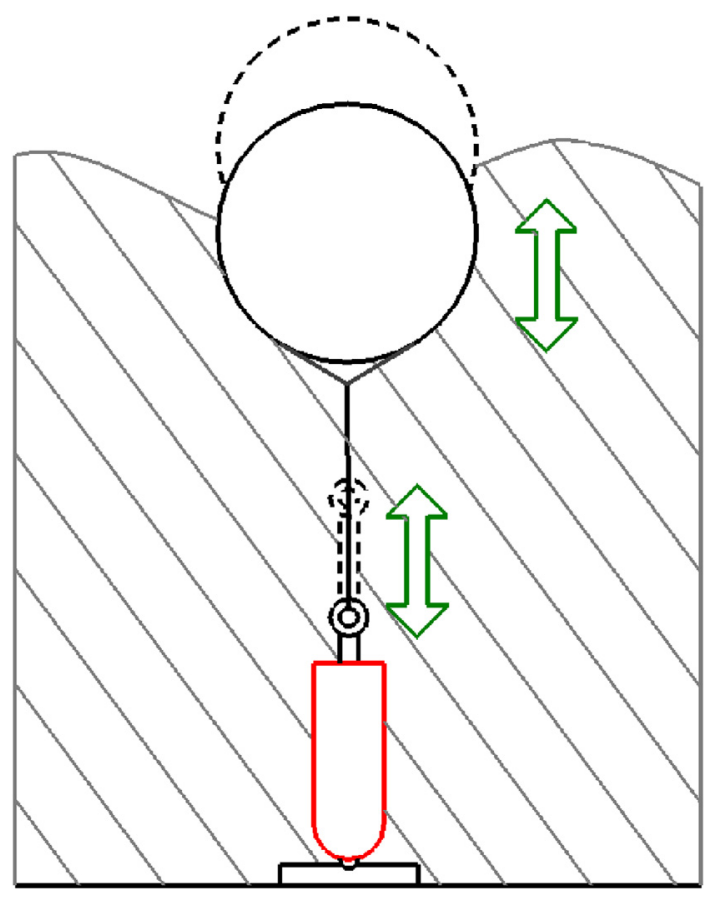

Fig. 9. Schematic of the spherical heaving PA studied in this paper. least in magnitude. The reference PTO force $F_{P T O}^{*}$ for the WEC is defined via Coulomb damping in the consP hydraulic PTO configuration, while resistive control is used in the varP configuration. The reference PTO forces, defined following Coulomb damping force and resistive control, are respectively given as,

$F_{P T O}^{*}=C_{P T O}$

$F_{P T O}^{*}=-B_{P T O} \dot{x}_{a b s}$

where $C_{\text {PTO }}$ is the Coulomb damping and $B_{\text {PTO }}$ the linear damping. Control parameters $C_{\text {РТО }}$ and $B_{\text {РTO }}$ are determined so that the force in both hydraulic PTO configurations is similar.

Table 1 presents the efficiencies of the different conversion stages, including the essential components of the hydraulic PTO, the efficiency of the PTO system as a whole $\left(\eta_{\text {Рто }}\right)$ and the W2W efficiency $\left(\eta_{W 2 W}\right)$. In addition, hydrodynamic power absorption efficiency $\left(\eta_{\text {wave }}\right)$ is computed using the ratio of the absorbed power to the power available in the wave, as in Ref. [52].

Fig. 10(a) and (b) illustrate the velocity of the spherical PA and the PTO force applied by the hydraulic cylinder on the absorber, respectively, for consP and varP hydraulic PTO configurations. The velocity profile shown in Fig. 10 (a) shows the different absorption modes for each hydraulic configuration, which shows higher peak values and less sharp edges in the varP case, compared to the cons $P$ case. Differences between cons $P$ and varP are more pronounced in Fig. 10 (b), where the force profile in the consP case is similar to a coulomb force, while the force profile in the varP case broadly follows the profile of the velocity.

Power outputs from the different conversion stages are shown in Fig. 10, where the absorbed power signal is always positive for the varP hydraulic PTO configuration, while negative values can be observed in the cons $P$ case. These negative values in the consP hydraulic PTO configuration appear when the absorber reaches its final position and the check valves close. At this point, the absorber starts moving in the opposite direction almost instantaneously, while the pressure in the cylinder chambers and, as a consequence, the force, needs more time to change. For a short interval of time, the signs of the velocity and the force are the same, resulting in negative absorbed power results. Apart from the negative values, peaks in the absorbed power signal are twice as high as in the case of the varP hydraulic PTO than in the consP case. As a result, absorption efficiency in Table 1 is almost 60\% higher in the case of the varP hydraulic PTO configuration. It should be noted that power absorption can be improved in both cases, optimising control parameters $C_{\text {PTO }}$ and $B_{\text {PTO }}$ in Equations (32) and (33), respectively, or, in the case of the varP configuration, by implementing real-time energy maximising control strategies, such as model-predictive [53], pseudo-spectral [54] or moment domain control [55]. However, limitations of the consP hydraulic PTO configuration, due to the high-pressure accumulators installed between the hydraulic cylinder and motor, as described in Section 2.2, suggest that absorbed power will always be higher in the varP case.

However, due to these high-pressure accumulator in the consP hydraulic PTO configuration, the output electrical power signal is smooth and practically constant, as illustrated in Fig. 11 (a), which

Table 1

Efficiency of the different components in the W2W model for constant- and variable-pressure PTO configurations.

\begin{tabular}{|c|c|c|c|c|c|c|c|c|c|c|}
\hline PTO & $\eta_{\text {Wave }}$ & $\eta_{C y l}$ & $\eta_{M o t}$ & $\eta_{H y}$ & $\eta_{\text {Gen }}$ & $\eta_{I n v}$ & $\eta_{\text {РTO }}$ & $\eta_{W 2 W}$ & $P_{\text {grid }}^{a v}$ & where \\
\hline \multicolumn{11}{|c|}{$\overline{\text { configuration }}$} \\
\hline consP & 10.22 & 97.96 & 92.73 & 90.84 & 87.51 & - & 79.49 & 8.17 & $7.39 \mathrm{~kW}$ & $\eta=P_{\text {out }} / P_{\text {in }} \times 100[\%]$ \\
\hline varP & 16.15 & 95.27 & 72.92 & 71.91 & 76.63 & 92.47 & 51.67 & 8.34 & $7.54 \mathrm{~kW}$ & \\
\hline
\end{tabular}


(a)
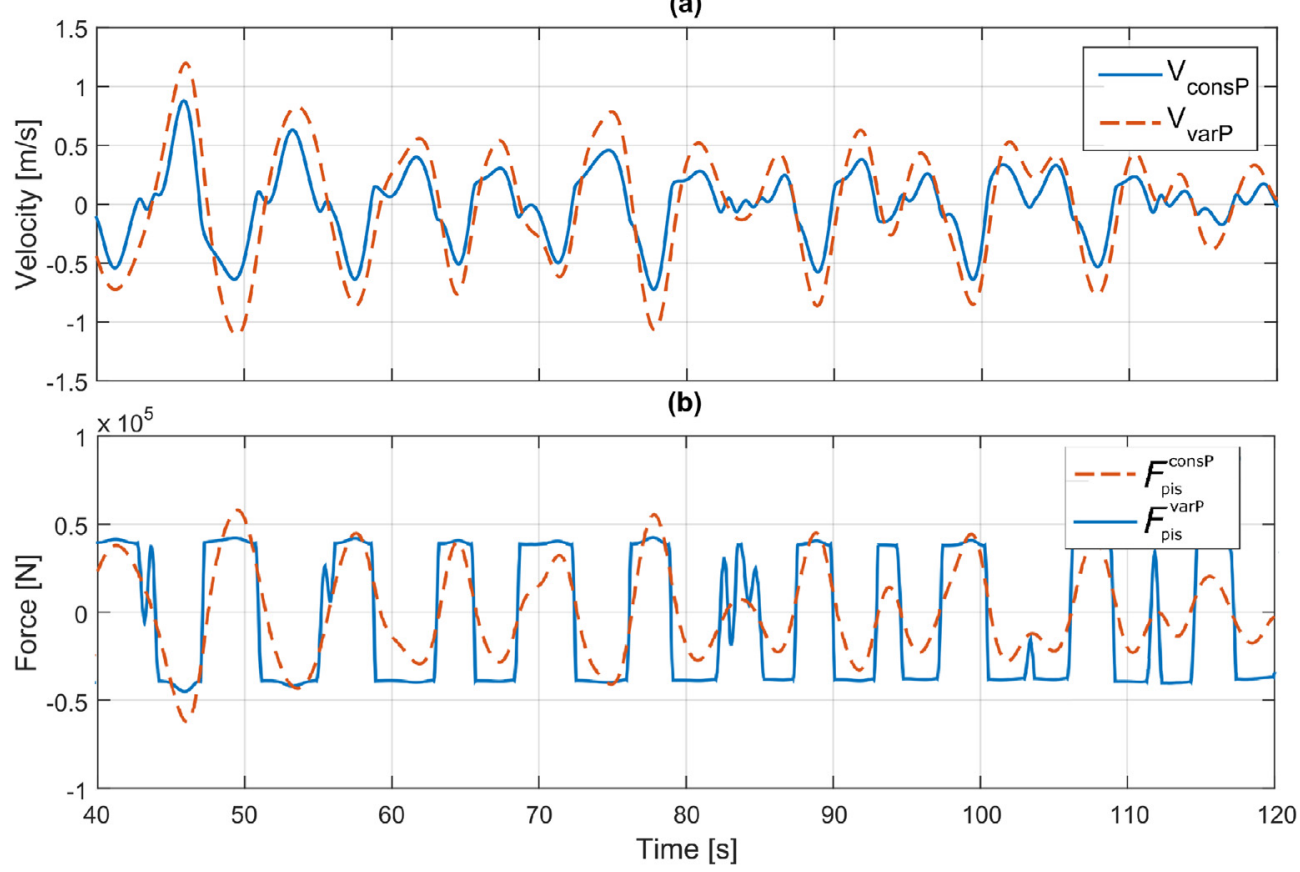

Fig. 10. Absorption characteristics of the constant- and variable-pressure configurations: (a) device velocity and (b) piston force.
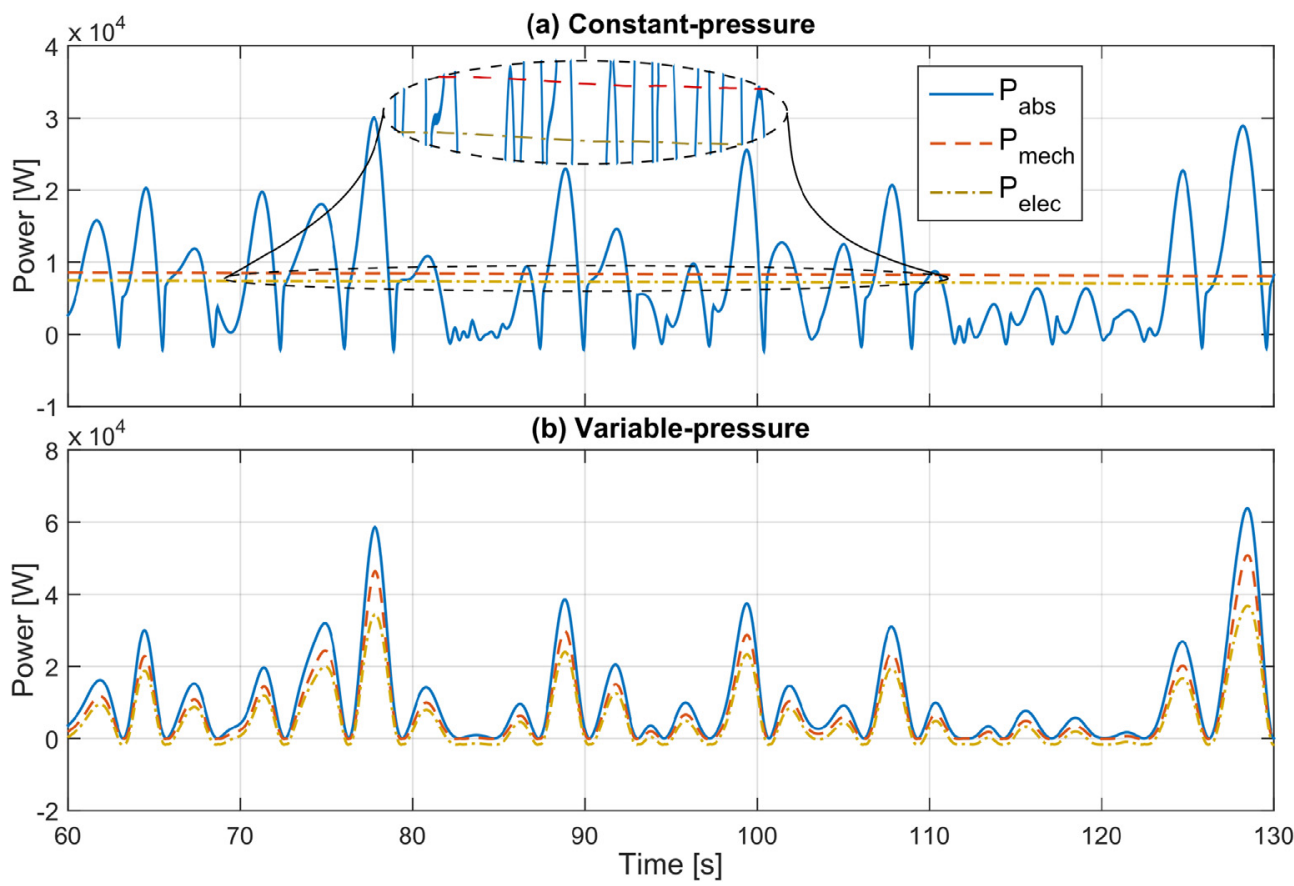

Fig. 11. Absorbed, mechanical and electrical power for the constant- (a) and variable-pressure (b) configurations

implies potentially higher hydraulic motor efficiency, as shown in Table 1. Mechanical and electric power outputs shown in Fig. 11 (a) appear to be perfectly flat because a very large accumulator is implemented $(1000 \mathrm{~L})$. However, small oscillations, due to the volume and pressure variations in the accumulator, can be observed in the zoomed dashed circle. In addition, since the generator operates at constant speed, the generator can be connected directly to the grid, removing power losses due to the inverters.
In contrast, the electrical power signal in the varP hydraulic PTO configuration, as illustrated in Fig. 11 (b), follows the profile of the absorbed power, which considerably reduces the PTO efficiency (approximately a 30\% reduction compared to the consP hydraulic PTO configuration), as shown in Table 1. Nevertheless, the W2W efficiency in the varP hydraulic PTO configuration is higher than in the consP PTO configuration. Indeed, an improvement of the PTO efficiency in the varP hydraulic PTO configuration is to be expected when the rotational speed of the electric generator and the 
hydraulic motor is actively controlled [56]. The rotational speed is held constant in the results shown in this paper.

It has been demonstrated that a higher PTO efficiency does not necessarily imply a higher W2W efficiency, which reinforces the need for a holistic consideration of the WEC performance to accurately maximise the final power generation.

\section{Conclusion}

The present paper presents a unique high-fidelity wave-to-wire model for wave energy converters that is generic, in the sense that different absorbers and hydraulic power take-off systems can be accommodated with relative ease, includes precise and balanced models at each conversion stage, has been validated against highfidelity software and experimental tests, and is computationally efficient.

The complexity and high computational requirements of the high-fidelity model are mitigated with a multi-rate integration scheme, drastically reducing computational requirements for a very similar fidelity. In addition, the selection of the integration method and method-order for each conversion stage is not a trivial decision. The very fast compressibility dynamics included in the hydraulic power take-off system lead to significant instabilities or very small time-steps that imply high computational requirements, unless the integration method is adequately selected.

The selection/optimisation of the different conversion stages based on studies where these conversion stages are analysed isolated from the rest of the drivetrain does not necessarily provide the best solution to generate energy from ocean waves. In fact, the hydraulic power take-off configuration that allows for higher efficiencies of the components in the power take-off system, or the whole power take-off system, may limit the power absorption from ocean waves, and result in lower electricity generation. The final design of a wave energy converter is driven by economical figures, but energy generation capabilities play a crucial role, which should be assessed analysing the holistic performance of the wave energy converter.

Including all the relevant nonlinear dynamics, losses and constraints in the mathematical models employed for the holistic evaluation of wave energy converter's behaviour is essential. Key decisions in the early stages of development of wave energy converters, such as the selection of absorber's size or the power takeoff system, require trustworthy results that can be obtained either via expensive experimental studies or high-fidelity mathematical models. The latter can help to delay expensive experiments and avoid making erroneous decisions for a relatively low cost.

\section{Acknowledgement}

This material is based upon works supported by the Science Foundation Ireland under Grant No. 13/IA/1886.

\section{References}

[1] G. Bacelli, R. Genest, J.V. Ringwood, Nonlinear control of flap-type wave energy converter with a non-ideal power take-off system, Annu. Rev. Contr. 40 (2015) 116-126, https://doi.org/10.1016/j.arcontrol.2015.09.006.

[2] M. Penalba, J.V. Ringwood, A review of wave-to-wire models for wave energy converters, Energies 9 (7) (2016) 506, https://doi.org/10.3390/en9070506.

[3] P. Igic, Z. Zhou, W. Knapp, J. MacEnri, H.C. Sorensen, E. Friis-Madsen, Multimegawatt offshore wave energy converters - electrical system configuration and generator control strategy, IET Renew. Power Gener. 5 (1) (2011) 10-17, https://doi.org/10.1049/iet-rpg.2009.0090.

[4] M. Amundarain, M. Alberdi, A.J. Garrido, I. Garrido, Modeling and simulation of wave energy generation plants: output power control, IEEE Trans. Ind. Electron. 58 (1) (2011) 105-117, https://doi.org/10.1109/TIE.2010.2047827.

[5] H. Bailey, B.R. Robertson, B.J. Buckham, Wave-to-wire simulation of a floating oscillating water column wave energy converter, Ocean Eng. 125 (2016)
248-260, https://doi.org/10.1016/j.oceaneng.2016.08.017.

[6] C. Josset, A. Babarit, A.H. Clément, A wave-to-wire model of the searev wave energy converter, Proc. IME M J. Eng. Marit. Environ. 221 (2) (2007) 81-93, https://doi.org/10.1243/14750902JEME48.

[7] P. Ricci, J. Lopez, M. Santos, P. Ruiz-Minguela, J.L. Villate, F. Salcedo, A.F.O. Falcão, Control strategies for a wave energy converter connected to a hydraulic power take-off, IET Renew. Power Gener. 5 (3) (2011) 234-244, https://doi.org/10.1049/iet-rpg.2009.0197.

[8] R.H. Hansen, M.M. Kramer, E. Vidal, Discrete displacement hydraulic power take-off system for the wavestar wave energy converter, Energies 6 (8) (2013) 4001-4044, https://doi.org/10.3390/en6084001.

[9] P.B. Garcia-Rosa, J.P. Vilela Soares Cunha, F. Lizarralde, S.F. Estefen, I.R. Machado, E.H. Watanabe, Wave-to-wire model and energy storage analysis of an ocean wave energy hyperbaric converter, IEEE J. Ocean. Eng. 39 (2) (2014) 386-397, https://doi.org/10.1109/JOE.2013.2260916.

[10] H. Bailey, J.P. Ortiz, B. Robertson, B.J. Buckhamn, R.S. Nicoll, A methodology for wave-to-wire wec simulations, in: Proceedings of the 2nd Marine Energy Technology Symposium (METS), Seattle, WA, 2014.

[11] D.I. Forehand, A.E. Kiprakis, A.J. Nambiar, A.R. Wallace, A fully coupled waveto-wire model of an array of wave energy converters, IEEE Trans. Sustain. Energy 99 (2015) 1-11, https://doi.org/10.1109/TSTE.2015.2476960.

[12] E. Tedeschi, M. Carraro, M. Molinas, P. Mattavelli, Effect of control strategies and power take-off efficiency on the power capture from sea waves, IEEE Trans. Energy Convers. 26 (4) (2011) 1088-1098, https://doi.org/10.1109/ TEC.2011.2164798.

[13] J. Sjolte, Marine Renewable Energy Conversion: Grid and Off-grid Modeling, Design and Operation, Ph.D. thesis, Norges teknisk-naturvitenskapelige universitet (NTNU), Fakultet for informasjonsteknologi, matematikk og elektroteknikk, Institutt for elkraftteknikk, 2014.

[14] R.K. Holm, N.I. Berg, M. Walkusch, P.O. Rasmussen, R.H. Hansen, Design of a magnetic lead screw for wave energy conversion, IEEE Trans. Ind. Appl. 49 (6) (2013) 2699-2708, https://doi.org/10.1109/TIA.2013.2264272.

[15] F. Wu, X.-P. Zhang, P. Ju, M.J. Sterling, Modeling and control of aws-based wave energy conversion system integrated into power grid, IEEE Trans. Power Syst. 23 (3) (2008) 1196-1204, https://doi.org/10.1109/ TPWRS.2008.922530.

[16] A.C. O'Sullivan, G. Lightbody, Co-design of a wave energy converter using constrained predictive control, Renew. Energy 102 (Part A) (2017) 142-156, https://doi.org/10.1016/j.renene.2016.10.034.

[17] M. Lawson, Y.-H. Yu, A. Nelessen, K. Ruehl, C. Michelen, Implementing nonlinear buoyancy and excitation forces in the wec-sim wave energy converter modeling tool, in: ASME 2014 33rd International Conference on Ocean, Offshore and Arctic Engineering, San Francisco, USA, vol. 9B, Ocean Renewable Energy, 2014, https://doi.org/10.1115/OMAE2014-24445 p. V09BT09A043.

[18] R. So, A. Simmons, T. Brekken, K. Ruehl, C. Michelen, Development of pto-sim: a power performance module for the open-source wave energy converter code wec-sim, in: ASME 2015 34th International Conference on Ocean, Offshore and Arctic Engineering, vol. 9, Ocean Renewable Energy, American Society of Mechanical Engineers, St. John's, Newfoundland, Canada, 2015, https://doi.org/10.1115/OMAE2015-42074 p. V009T09A032.

[19] J. Weber, WEC Technology Readiness and Performance Matrix-finding the best research technology development trajectory, in: Proceedings of the 4th International Conference on Ocean Energy, Dublin, 2012.

[20] A. Mérigaud, J.V. Ringwood, Free-surface time-series generation for wave energy applications, IEEE J. Ocean. Eng. 43 (1) (2018) 19-35, https://doi.org/ 10.1109/JOE.2017.2691199.

[21] M. Penalba, G. Giorgi, J.V. Ringwood, Mathematical modelling of wave energy converters: a review of nonlinear approaches, Renew. Sustain. Energy Rev. 78 (2017) 1188-1207, https://doi.org/10.1016/j.rser.2016.11.137.

[22] G. Giorgi, J.V. Ringwood, Computationally efficient nonlinear froude-krylov force calculations for heaving axisymmetric wave energy point absorbers, J. Ocean Eng. Mar. Energy (2016) 1-13, https://doi.org/10.1007/s40722-0160066-2.

[23] G. Giorgi, M. Penalba, J.V. Ringwood, Nonlinear hydrodynamic force relevance for different wave energy converter types, in: Proceedings of the 3rd Asian Wave and Tidal Energy Conference, 2016, pp. 154-162.

[24] G. Giorgi, J. V. Ringwood, A compact 6-dof nonlinear wave energy device model for power assessment, Accepted in IEEE Transactions on Sustainable Energy.

[25] W.E. Cummins, The Impulse Response Function and Ship Motions, Tech. rep., DTIC Document, 1962.

[26] M. Penalba, T. Kelly, J.V. Ringwood, Using NEMOH for modelling wave energy converters: a comparative study with WAMIT, in: 12th European Wave and Tidal Energy Conference, Cork, No. 631, 2017, pp. 1-10.

[27] M. Penalba, A. Mérigaud, J.-C. Gilloteaux, J.V. Ringwood, Influence of nonlinear froude-krylov forces on the performance of two wave energy points absorbers, J. Ocean Eng. Mar. Energy 3 (3) (2017) 209-220, https://doi.org/ 10.1007/s40722-017-0082-X.

[28] J. R. Morison, M. P. O'Brien, J. W. Johnson, S. A. Schaaf, The forces exerted by surface waves on piles, Petrol. Trans. AIME. Vol. 189, pp. 149-157 2 (5). https://dx.doi.org/10.2118/950149-G.

[29] G. Giorgi, M. Penalba, J.V. Ringwood, Nonlinear hydrodynamic models for heaving buoy wave energy converters, in: Proceedings of the 3rd Asian Wave and Tidal Energy Conference, 2016, pp. 144-153.

[30] R. Henderson, Design, simulation, and testing of a novel hydraulic power take- 
off system for the pelamis wave energy converter, Renew. Energy 31 (2) (2006) 271-283, https://doi.org/10.1016/j.renene.2005.08.021. Marine Energy.

[31] R.H. Hansen, Design and Control of the Powertake-off System for a Wave Energy Converter with Multiple Absorbers, Ph.D. thesis, Videnbasen for Aalborg UniversitetVBN, Aalborg UniversitetAalborg University, Det TekniskNaturvidenskabelige FakultetThe Faculty of Engineering and Science, 2013.

[32] A. Henry, K. Doherty, L. Cameron, T. Whittaker, R. Doherty, Advances in the design of the oyster wave energy converter, in: RINA Marine and Offshore Energy Conference, 2010.

[33] J. Fiévez, T. Sawyer, Lessons learned from building and operating a grid connected wave energy plant, in: Proceedings of the 11th European Wave and Tidal Energy Conference, Nantes, No. 08D1-4, 2015.

[34] J. Lucas, M. Livingstone, M. Vuorinen, J. Cruz, Development of a wave energy converter (wec) design tool-application to the waveroller wec including validation of numerical estimates, in: Proceedings of the 4th International Conference on Ocean Energies, Dublin, 2012.

[35] Y. Kamizuru, Development of Hydrostatic Drive Trains for Wave Energy Converters, Ph.D. thesis, RWTH Aachen University, 2014.

[36] G. Bacelli, J.V. Ringwood, Numerical optimal control of wave energy converters, IEEE Trans. Sustain. Energy 6 (2) (2015) 294-302, https://doi.org/ 10.1109/TSTE.2014.2371536.

[37] M. Jelali, A. Kroll, Hydraulic Servo-systems: Modelling, Identification and Control, Springer Science \& Business Media, 2012.

[38] W. Schlöesser, Mathematical model for displacement pumps and motors, Hydraul. Power Trans. (1961) 252-257.

[39] W. Schlösser, The overall efficiency of positive-displacement pumps, in: In BHRA Fluid Power Symposium, 1968, pp. 34-48.

[40] M. Penalba, N. Sell, A. Hillis, J. Ringwood, Validating a wave-to-wire model for a wave energy converter - Part I: the hydraulic transmission system, Energies 10 (7) (2017) 977, https://doi.org/10.3390/en10070977.

[41] C. Signorelli, C. Villegas, J.V. Ringwood, Hardware-in-the-loop simulation of a heaving wave energy converter, in: Proceedings of the 9th European Wave and Tidal Energy Conference (EWTEC), School of Civil Engineering and the Environment, University of Southampton, 2011.

[42] J. Sjolte, G. Tjensvoll, M. Molinas, Power collection from wave energy farms, Appl. Sci. 3 (2) (2013) 420-436, https://doi.org/10.3390/app3020420.

[43] P.C. Krause, O. Wasynczuk, S.D. Sudhoff, S. Pekarek, Analysis of Electric
Machinery and Drive Systems, third ed., IEEE Press Series on Power Engineering, Wiley-Blackwell, 2013.

[44] M. Penalba, J.-A. Cortajarena, J.V. Ringwood, Validating a wave-to-wire model for a wave energy converter - Part II: the electrical system, Energies 10 (7) (2017) 1002, https://doi.org/10.3390/en10071002.

[45] J. Mondol, Sizing of grid-connected photovoltaic systems, in: Society of Photooptical Instrumentation Engineers, vol. 4, Citeseer, 2007.

[46] C.W. Gear, D. Wells, Multirate linear multistep methods, BIT Num. Math. 24 (4) (1984) 484-502, https://doi.org/10.1007/BF01934907.

[47] C. Engstler, C. Lubich, Multirate extrapolation methods for differential equations with different time scales, Computing 58 (2) (1997) 173-185, https:// doi.org/10.1007/BF02684438.

[48] F.L. Severence, System Modeling and Simulation: an Introduction, John Wiley \& Sons, 2009.

[49] E. Hairer, S. Nørsett, G. Wanner, Solving Ordinary Differential Equations I: Nonstiff Problems, Springer Series in Computational Mathematics Edition, Springer, 1993.

[50] A. Iserles, A First Course in the Numerical Analysis of Differential Equations, no. 44, Cambridge university press, 2009.

[51] U.M. Ascher, L.R. Petzold, Computer Methods for Ordinary Differential Equations and Differential-algebraic Equations, vol. 61, Siam, 1998.

[52] R. Takaramoto, M. Kashiwagi, K. Sakai, et al., Wave energy absorption in irregular waves by a floating body equipped with interior rotating electric power generator, in: The 24th International Ocean and Polar Engineering Conference, International Society of Offshore and Polar Engineers, 2014.

[53] N. Faedo, S. Olaya, J.V. Ringwood, Optimal control, mpc and mpc-like algorithms for wave energy systems: an overview, IFAC J. Syst. Contr. 1 (2017) 37-56.

[54] R. Genest, J.V. Ringwood, Receding horizon pseudospectral control for energy maximization with application to wave energy devices, IEEE Trans. Contr. Syst. Technol. 25 (1) (2017) 29-38, https://doi.org/10.1109/ TCST.2016.2554524.

[55] N. Faedo, G. Scarciotti, A. Astolfi, J. Ringwood, Energy-maximising control of wave energy converters using a moment-domain representation, Contr. Eng. Pract. 81 (2018) 85-96.

[56] R.H. Hansen, T.O. Andersen, H.C. Pedersen, Model based design of efficient power take-off systems for wave energy converters, in: Proceedings of the 12th Scandinavian International Conference on Fluid Power, 2011, pp. 1-15. 